MEMÓRIA

\title{
Emílio Goeldi (1859-1917) e a Institucionalização das Ciências Naturais na Amazônia
}

Nelson Sanjad*

A fundação do Museu Paraense, em 1866, é usualmente considerada um marco na história das ciências no Brasil, principalmente em razão da diversificação do cenário científico na segunda metade do século XIX, por meio da criação de museus de história natural, comissões geológicas, institutos agrícolas e bacteriológicos (Schwartzman, 1979; Dantes, 1979-1980; Lopes, 1997). Contudo, e apesar de criado em meados do século, as atividades científicas do Museu Paraense foram incrementadas somente a partir de 1894, quando o zoólogo suíço Emílio Goeldi (1859-1917) assumiu a direção do museu. Apoiado pelos primeiros governantes republicanos do Pará, Goeldi reformou a instituição dando-lhe um novo nome (Museu Paraense de História Natural e Etnografia), um regimento, uma produtiva equipe de cientistas e infra-estrutura adequada para a investigação e para as atividades museológicas (Sanjad, 2005).

O que pretendemos destacar aqui é a dupla importância de Emílio Goeldi para a institucionalização da ciência na Amazônia. Se por um lado o zoólogo ajudou a consolidar o Museu Paraense, inserindo-o no movimento científico nacional e internacional, por outro lado ele também foi responsável, pela primeira vez no país, pela formulação de um projeto científico claro e coerente para a Amazônia. Esse projeto teve como núcleo o próprio Museu Paraense, a

\footnotetext{
* Doutor em História das Ciências pela Casa de Oswaldo Cruz/Fiocruz. Tecnologista do Museu Paraense Emílio Goeldi/ MCT e professor do Centro Universitário do Pará/CESUPA. E-mail: nsanjad@museu-goeldi.br.

N.E.: os Editores agradecem a Monika Heringer, da ABIPTI, pela colaboração na seção MEMÓRIA deste número.
} 
partir do qual Goeldi e seus colaboradores deram início à sistematização do conhecimento científico sobre a região.

Nesse sentido, os documentos aqui transcritos demonstram não apenas como Goeldi concebeu o Museu Paraense, mas também como entendia o papel ou a missão de uma instituição científica na Amazônia. O primeiro deles é uma Carta Circular que o zoólogo divulgou logo após assinar o contrato com o Governo do Pará, em 22 de março de 1894, e posteriormente publicou no primeiro fascículo do Boletim do Museu Paraense de História Natural e Etnografia (Goeldi, 1894a). Aí estão contidas a estrutura básica do Museu Paraense e as áreas científicas que Goeldi considerava prioritárias, particularmente a zoologia e a botânica.

O segundo documento é a carta de demissão de Goeldi, endereçada ao governador do Pará em 7 de março de 1907, na qual faz uma avaliação de sua longa gestão à frente do museu e também recomendaçôes sobre o futuro da instituição (manuscrito inédito). Ambos os documentos são testemunhos de uma época em que a ciência despontava como setor estratégico para o Estado brasileiro, de uma concepção de ciência como valor a ser cultivado pela sociedade e de um projeto científico que vale a pena ser lembrado, independentemente de julgamentos outros que não sua própria coerência interna, histórica e culturalmente determinada.

\section{O projeto científico do Museu Paraense: "Fauna do Brasil"}

No Brasil, Goeldi manifestou um interesse diversificado pela fauna, que revela seu projeto de publicar um compêndio sobre a "Fauna do Brasil", do qual as monografias sobre mamíferos e aves, publicadas em 1893 e 1894, respectivamente, foram os anúncios. Goeldi registrou esse projeto no Regulamento do Museu Paraense, quando afirmou que evitaria o "nocivo esfacelamento literário" e concentraria as atividades da instituição na "exploração metódica e racional" do Brasil, tal como Karl Friedrich Philipp von Martius (17941868) realizara na "Flora Brasiliensis" (Museu Paraense, 1894:27).

Posicionamento semelhante o zoólogo anunciou na sua Carta Circular, quando escreveu que a zoologia e a botânica eram suas ciências prediletas e que seriam prioridades no seu programa de trabalho (Goeldi, 1894a:9). A promessa 
pode ser atestada pela quantidade de artigos publicados no Boletim do Museu Paraense entre 1894 e 1914, com sensível maioria para as áreas de zoologia (33\%) e botânica (28\%) (Lopes, 1997:262); pela quantidade de cientistas contratados pelo diretor, em sua maioria zoólogos (Sanjad, 2005:193-195); e pela maneira como concebeu e organizou as investigaçóes do Museu Paraense, tendo como principais veículos de divulgação o Boletim e as Memórias do Museu Paraense de História Natural e Etnografia, estas publicadas a partir de 1900.

No primeiro fascículo do Boletim, publicado em setembro de 1894, já é possível antever o tipo de texto que Goeldi destinou à revista. Ele reúne relatórios administrativos, textos memorialísticos, um relato de viagem e dois estudos taxonômicos do diretor do museu, elaborados com dados e coleções trazidos do Rio de Janeiro. O primeiro é o complemento de um estudo anterior sobre a fauna de aranhas brasileiras, publicado em 1892 (Goeldi, 1892, 1894c). O segundo relata os intercâmbios de Goeldi com especialistas em classificação de vermes, a partir dos quais foram identificadas novas espécies ou registrada a ocorrência no Brasil de animais pouco conhecidos (Goeldi, 1894d).

O mesmo empenho compilatório pode ser visto nos estudos posteriores que apareceram no Boletim e nas Memórias, sobre miriápodos (Goeldi, 1895b), aves (Goeldi, 1896a, 1900-1906), répteis (Goeldi, 1896b, 1902a, 1906), mamíferos (1902b) e peixes (Goeldi, 1898), nos quais o autor ora colige material próprio, ora resume dados da bibliografia, com a intenção de preparar terreno para trabalhos de maior envergadura.

Goeldi também publicou no Boletim traduções comentadas de textos relativos à fauna amazônica, como "Os Símios (macacos) da Amazônia”, de Alfred Russel Wallace (1823-1913) (Wallace, 1896); "Os hóspedes das formigas e dos térmites ('cupim') no Brasil”, do jesuíta tirolês Erich Wasmann (1859-1931) (Wasmann, 1895); e "A Fauna do Pará", de Fr. Dahl, professor da Universidade de Kiel, Alemanha (Dahl, 1896). Os dois primeiros foram considerados clássicos da literatura zoológica brasileira, mas o terceiro, resultante da Plankton-Expedition, que visitou a região em 1889, foi escolhido com o fim de corrigir vários equívocos que, segundo Goeldi, o autor cometeu em seu trabalho, vítima das "excursões e visitas rápidas (...) [que] não podem dar resultado de todo exato (...)” (Dahl, 1896:372, nota 1). Essa seria a primeira das reprimendas que Goeldi deu nos autores "apressados", posicionando-se 
sempre como um cientista capaz de julgar, habilitar ou condenar outros cientistas que escreviam sobre a fauna amazônica.

Além dos estudos próprios e das traduções, Goeldi coordenou outros autores que pudessem contribuir com seu projeto. O primeiro deles foi August Forel (1848-1931), psiquiatra e entomólogo suíço da Universidade de Zurique, que escreveu copioso trabalho para o Boletim, "A Fauna das Formigas do Brasil” (Forel, 1895). O francês Pierre Émile Gounelle (1850-1914), do Museu de História Natural de Paris, também foi convidado a participar do esforço de compilação da fauna local. Publicou no Boletim o resultado das coletas de coleópteros que efetuou em Belém no ano de 1895 (Gounelle, 1897).

Geralmente, ao final das expedições realizadas pelo museu, Goeldi enviava muitos espécimes para a Europa a fim de serem identificados por especialistas. Em seguida, pedia que estes publicassem suas descrições ou compilações no Boletim; ou então traduzia os trabalhos publicados em outras línguas que versavam sobre as coleçôes do Museu Paraense. Foram os casos de Oldfield Thomas (1858-1929), chefe da seção de mamíferos do Museu Britânico, que publicou sobre a coleção de morcegos (Thomas, 1904), e de Theophil Studer (1845-1922), professor de zoologia da Universidade de Berna, que escreveu sobre cães e raposas (Studer, 1904). Foi também o caso de Henry Wilfred Brölemann (1860-1933), da Sociedade Entomológica da França. Este descreveu duas espécies de miriápodos coletados por Goeldi na Serra dos Órgãos e no horto botânico do Museu Paraense. Nas suas notas, Brölemann não deixou de agradecer ao "sábio Diretor do Museu Paraense (cuja amabilidade para com os especialistas é tão notória que não precisa de novos encômios)" (Brölemann, 1900:66).

A expressão de Brölemann ilustra o intenso intercâmbio de Goeldi com outros cientistas. O diretor do Museu Paraense não foi grande coletor (em termos quantitativos) e descreveu poucas espécies, se o compararmos com seus colaboradores estrangeiros e mesmo com seus colegas do museu, Jacques Huber (1867-1914), Adolpho Ducke (1876-1959) e Emília Snethlage (18681929). ${ }^{1}$ Talvez por esse motivo o zoólogo tenha feito questão de registrar e

\footnotetext{
As viagens de Goeldi pela Amazônia resumiram-se a excursões aos arredores de Belém, ao nordeste do Pará, à llha do Marajó, ao rio Capim, ao baixo Tocantins e à costa do Amapá, o ponto mais distante que chegou da capital. No Museu Paraense, descreveu treze espécies, sendo dois peixes, uma doninha, duas aves, três macacos, uma rã e quatro insetos. Se considerarmos as espécies descritas por Goeldi no Museu Nacional do Rio de Janeiro, onde trabalhou de 1884 a 1890, devemos acrescentar mais oito animais nessa lista, sendo um réptil, quatro insetos, dois crustáceos e um verme (Sanjad, 2005).
} 
divulgar suas atividades como fornecedor de espécimes brasileiros para outros cientistas, tal como Brölemann reconheceu. Nesse sentido, em 1899 publicou um folheto com três listas: dos animais e plantas que "descobriu" e foram classificados por outros especialistas para honrá-lo, como o macaco Hapale goeldii (atual Calimico goeldii, conhecido como mico-de-Goeldi), descrito em 1898 por Oldfield Thomas, do Museu Britânico; dos animais que "descobriu" e foram descritos por outros especialistas; e dos animais que ele próprio descreveu. Esse folheto recebeu sete suplementos até 1904, nos quais o zoólogo atualizava as listas acrescentando as espécies descritas em cada intervalo (Goeldi, 1899-1904). Cabe ressaltar que Goeldi apresentou como suas "descobertas" muitos exemplares coletados pela equipe do Museu Paraense e por amadores residentes em Belém. Estão nestas categorias os animais provenientes dos rios Tapajós e Purus, locais onde o zoólogo nunca esteve.

Podemos medir a "amabilidade" de Goeldi para com os cientistas europeus por meio desses folhetos. Por exemplo, entre 1894 e 1904, os espécimes amazônicos enviados pelo zoólogo para o estrangeiro resultaram na descrição de 86 espécies novas para a ciência, excluindo as descritas pelos próprios funcionários do museu. Naquele rol registramos mamíferos (5), peixes (6), insetos (58), aracnídeos (5), espongiário (1), carrapatos (3), miriápodos (6) e plantas (2). Os cientistas que receberam e descreveram as espécies foram alguns dos mais importantes zoólogos da época, como Oldfield Thomas (1858-1929), George Albert Boulenger (1858-1937), Frederic Theobald (1868-1930), Édouard Louis Trouessart (1842-1927), Theodore Dru Alison Cockerell (1866-1948), dentre outros. ${ }^{2}$

É possível extrair algumas conclusões desses dados. A primeira é que Goeldi utilizou esse tipo de intercâmbio para aproximar o Museu Paraense (e a si próprio) dos grandes museus europeus, fornecendo aos seus cientistas animais pouco conhecidos (ou totalmente desconhecidos) para a ciência. Na impossibilidade de descrever ele mesmo cada animal - pois as incipientes coleções científicas e a biblioteca do Museu Paraense ainda não permitiam uma identificação segura das espécies - Goeldi valorizou seu cargo de diretor de um museu localizado

\footnotetext{
Se somarmos essas remessas aos animais e plantas originários do Rio de Janeiro, São Paulo, Minas Gerais, Espírito Santo e Bahia, que Goeldi coletou, comprou ou recebeu como doação, teremos mais 233 novas espécies brasileiras para a ciência, dentre as quais sobressaem 165 aracnídeos descritos por Keyserling (139), Sörensen (15), Canestrini (6) e Marx (5).
} 
na Amazônia fornecendo regularmente coleções para museus estrangeiros e ganhando, assim, credibilidade e prestígio no meio científico internacional.

Esse procedimento, contudo, deve ser entendido dentro das dificuldades existentes em Belém e do projeto de Goeldi. Para o zoólogo, o importante era envolver o maior número possível de especialistas na classificação dos muitos animais que coletava ou mandava coletar - e de fato Goeldi conseguiu esse feito, estabelecendo uma rede epistolar com mais de 30 cientistas de diferentes nacionalidades. Mas, segundo o diretor do Museu Paraense, a descrição de novas espécies era apenas o passo inicial da tarefa do zoólogo. Mais importante seria conhecer os aspectos biológicos de cada animal, sua distribuição geográfica e seus hábitos ${ }^{3}$ - investigações possíveis somente a quem estava em permanente contato com a natureza local. Goeldi manifestou prematuramente essas idéias nos livros sobre aves e mamíferos brasileiros (Goeldi, 1893, 1894b) e certamente as tinha em mente quando propôs, na sua Carta Circular, a criação de duas estações biológicas vinculadas ao Museu Paraense, uma no rio Amazonas e outra em Bragança (PA). A elas estariam ligados, além das investigaçóes biológicas propriamente ditas, estudos sobre recursos pesqueiros (Goeldi, 1894a: 9), claramente inspirados nos trabalhos de Karl Möbius (1825-1908) e nos desenvolvidos na Estação Zoológica de Nápoles, onde Goeldi estudou no início da década de 1880.

Goeldi voltou ao assunto quando publicou o catálogo de mamíferos do Museu Paraense, divulgado não como uma simples lista, e sim como uma "coleção de comentários, que se cristalizavam ao redor de um eixo, (...) que, por sua vez, não é outra coisa, senão o resultado logicamente necessário da experiência local de 9 anos (...)" (Goeldi \& Hagmann, 1904:39). Esse mesmo princípio foi defendido regularmente em inúmeros trabalhos do diretor, como no seu estudo sobre a ave amazônica responsável pela disseminação da erva-depassarinho: "É bom lembrar que a denominação sistemática e diagnose de uma espécie é [sic] meramente o limiar para a entrada no conhecimento essencial de sua esfera de vida - uma pequena fração somente da soma total da história natural da espécie" (Goeldi, 1905:169).

\footnotetext{
Ao nos referirmos aos estudos "biológicos" de Goeldi, não utilizamos o termo tal como o entendemos atualmente (ou seja, estudos relacionados às ciências da vida), e sim ao conjunto de investigações que, no século XIX, ganhou esse nome para se distinguirem da sistemática, taxonomia, morfologia, embriologia, fisiologia e outros ramos característicos da época. O que distinguia a "biologia" no XIX era o estudo dos organismos no meio em que viviam, ou seja, sua alimentação, seus hábitos, sua reprodução, suas fases de vida, etc. (cf. Nyhart, 1996:432).
} 
Para Goeldi, os inventários faunísticos que elaborou e os que divulgou no Boletim do Museu Paraense tinham como fim a compilação de dados confiáveis para a organização de uma "Fauna do Brasil" - a qual deveria nascer como referência para o assunto, espécie de enciclopédia sem precedentes na literatura zoológica do país. Foi esse o projeto que Goeldi quis garantir para si e para o Museu Paraense. Nesse sentido, os trabalhos de outros autores que apareciam no boletim e as remessas de coleçôes para o estrangeiro guardavam coerência com os estudos faunísticos desenvolvidos e incentivados pelo diretor do museu, e confirmam a personificação científica da instituição, isto é, a simbiose (para usarmos uma metáfora biológica) entre interesses institucionais e pessoais, a qual requeria a submissão dos demais funcionários (e interesses) ao desiderato do diretor.

O que distinguiu o projeto de Goeldi dos demais museus de história natural da época foi seu empenho em ampliar o conhecimento biológico sobre as espécies e sua concentração na fauna amazônica, o que exigiu do diretor do Museu Paraense a articulação dos demais pesquisadores da instituição. Por exemplo, Adolpho Ducke aliou as viagens de coleta e a taxidermia à investigação científica propriamente dita, tornando-se em pouco tempo reconhecido por seus estudos taxonômicos de insetos sociais. Por sua vez, Hermann Meerwarth (1870-?) reviu criticamente a obra de 26 zoólogos que se dedicaram à primatologia americana, de Lineu a Goeldi. Os resultados foram a revisão das chaves genérica e específica para a classificação dos símios neotropicais e um primeiro exercício de distribuição geográfica dos principais gêneros. Meerwarth, assim como Goeldi vinha fazendo, valorizou seu trabalho a partir do local em que foi efetuado, dando-lhe credibilidade pelo fato de sua instituição estar na "pátria da grande maioria das espécies de símios americanos":

Somente a um instituto científico, situado na própria pátria destes símios neotropicos [sic], está reservada a ventura de trabalhar com sucesso neste problema e de projetar luz sobre a sistemática tão incerta elucidando o valor de umas tantas espécies estabelecidas mais conforme opiniões subjetivas e individuais do que sobre caracteres indubitavelmente existentes na natureza. (Meerwarth, 1897:122) 
Quanto a Gottfried Hagmann (1874-1946), foi encarregado por Goeldi de organizar os catálogos dos mamíferos e das aves existentes no museu. $\mathrm{O}$ primeiro foi elaborado conjuntamente pelo diretor e seu auxiliar, com informaçôes taxonômicas, anatômicas, biogeográficas e biológicas de 111 espécies. $\mathrm{Na}$ introdução, Goeldi afirmou que o museu mantinha-se "fiel ao seu programa de trabalho e pedanticamente [sic] conservador na esfera de atividade traçada pela sua lei básica, [que] se ocupa antes de tudo com a natureza da Amazônia”. Nesse aspecto, tinha uma "posição incontestavelmente privilegiada, reunindo tal soma de elementos e circunstâncias favoráveis para a confecção de um trabalho deste gênero como naturalmente não chegou a concentrar-se até aqui em lugar, tempo e mão alguma” (Goeldi \& Hagmann, 1904:39).

O catálogo de aves ganhou impulso quando Hagmann coligiu informações no "Catalogue of the Birds of British Museum" (1874-1898), extraindo de seus 27 volumes, segundo Goeldi, "o quinhão amazônico, para torná-lo útil para os nossos futuros planos, (...) na certeza que será bem vindo para aqueles que são interessados no conhecimento exato da fauna brasílica" (in Hagmann, 1902:277). Em seguida, Hagmann elaborou a chave sinonímica das aves descritas por Johann Baptist von Spix (1782-1826), Maximilian von WiedNeuwied (1782-1867), Karl Hermann Konrad Burmeister (1807-1892) e August von Pelzeln (1825-1891), comparando-as com o catálogo do Museu Britânico. Este era, segundo Goeldi, o meio adequado para "saber qual o nome científico atualmente adotado para esta ou aquela ave, por via de regra, navegando com passaportes diferentes nas diversas obras" (Hagmann, 1904:199).

O passo seguinte não seria dado por Hagmann, e sim por Snethlage. A zoóloga foi contratada com a missão específica de acelerar e dar continuidade às pesquisas ornitológicas do Museu Paraense, condensando os estudos prévios de Goeldi e Hagmann. O “Catálogo das Aves Amazônicas”, publicado em 1914, reuniu os resultados das pesquisas taxonômicas, biogeográficas e biológicas de Snethlage, as informações disponíveis na coleção ornitológica do Museu Paraense - então a maior existente sobre a avifauna amazônica - e também de outros museus. O catálogo é o melhor exemplo da concatenação das atividades científicas desenvolvidas ou incentivadas por Goeldi, e também o mais bem sucedido. Apesar de ter aparecido muito tempo depois de Goeldi ter deixado o museu, o catálogo de Snethlage seguiu exatamente o projeto que o zoólogo 
determinou para a instituição: a liderança nos estudos faunísticos e biológicos relacionados à Amazônia (Snethlage, 1914). ${ }^{4}$

Goeldi nunca publicou sua "Fauna do Brasil" e talvez tenha desistido dessa idéia ao se deparar com a imensa diversidade de formas de vida existente na Amazônia, que jogaria para o futuro a possibilidade de um inventário semelhante. Contudo, como vimos, seu projeto científico era claro, coerente e, até certo ponto, exeqüível com os recursos que dispunha, como demonstrou Snethlage.

\section{Goeldi e as ciências naturais no Brasil}

A longa gestão de Goeldi à frente do Museu Paraense, durante a qual reconstruiu, literalmente, a antiga instituição criada em meados do século XIX, pode ter significado a perda de sua saúde e anos de abnegação familiar, como o zoólogo informou em sua carta de demissão. Mas foi fundamental para a carreira do próprio Goeldi, uma vez que viveu em Belém seu período mais fértil cientificamente, para a consolidação da instituição que dirigiu e para o desenvolvimento das ciências naturais no Brasil.

Goeldi foi extremamente hábil na percepção dos vácuos de autoridade ${ }^{5}$ existentes no conhecimento zoológico da Amazônia, assim como na seleção de problemas científicos irresolutos e temas que se apresentavam ou emergiam como campos de batalha, como a evolução de aves, peixes e répteis. Sua decisão de concentrar as atividades do Museu Paraense na natureza amazônica está diretamente relacionada à receptividade que o assunto dispunha no meio científico internacional e também à carência de informaçôes sobre a região, cujas

\footnotetext{
4 A própria Snethlage (1914:2-3) afirmou a ascendência de Goeldi sobre o trabalho, reconhecendo que fora o zoólogo que idealizara o catálogo e que havia colocado "à disposição a sua rica experiência em coisas da ornitologia brasileira". Em outro trecho, Snethlage informou que empregara a nomenclatura técnica utilizada por Goeldi nos seus estudos: "Quanto à nomenclatura técnica, especialmente difícil numa língua onde a terminologia ornitológica quase não existia até há bem pouco tempo, empreguei o mais possível as expressões usadas pelo Dr. Goeldi nos seus trabalhos relativos à avifauna brasileira."

5 Segundo Ritvo (1997:13-14), discordâncias, ambigüidades e disputas foram permanentes no meio científico e no solo movediço da biologia do século XIX, como as que ocorreram em torno da fauna australiana, de difícil classificação para os taxonomistas e anatomistas: "Como as irregularidades da anatomia dos marsupiais e dos monotremas [subclasse do ornitorrinco] minaram as estruturas e suposições taxonômicas prévias, elas criaram um vácuo de autoridade zoológica, se não de poder. (...) Assim, a classificação de marsupiais e monotremas emergiu como um campo de batalha sobre o qual sistemas rivais e sistematas rivais puderam se engajar, algumas vezes discutindo diretamente o assunto, algumas vezes usando-o como um cavalo de batalha para matérias ainda maiores e profundas".
} 
principais fontes eram os viajantes estrangeiros e seus relatos, muitas vezes considerados limitados e equivocados. Assim, a agenda científica que o zoólogo elaborou para a instituição - combinando inventários faunísticos, estudos biológicos e questôes evolucionistas - visava, sobretudo, ocupar um espaço existente no meio científico europeu, (ainda) aberto para instituições e cientistas localizados fora do circuito principal de museus e universidades, desde que fossem especializados na fauna e na flora de locais considerados exóticos.

Nesse sentido, Goeldi seguiu por caminhos que também foram trilhados por outros museus ditos "coloniais", na medida em que manteve permanentemente uma interlocução com grandes museus europeus, como o Museu Britânico. Segundo Sheets-Pyenson (1988:15), o que teria caracterizado essas instituições localizadas na periferia do capitalismo europeu, fundadas e mantidas numa época de imperialismo acirrado, foi a "dependência da atividade científica [desenvolvida] no hinterland dos empreendimentos metropolitanos. A busca [pursuit] da história natural em particular tem sido vista como central no aprofundamento da desigualdade entre centro e periferia”.

Contudo, essa relação de dependência deve ser matizada, pois os próprios cientistas do século XIX, localizados nos grandes museus europeus, reconheciam que não dominavam todos os assuntos sob sua alçada. Era o caso da fauna amazônica, cujo conhecimento fragmentado e insuficiente era amplamente reconhecido pelos zoólogos, como Philip Lutley Sclater (1829-1913), secretário da Sociedade Zoológica de Londres durante 40 anos, grande correspondente de Goeldi e resenhista de seus escritos na revista The Ibis. Esse fato, na prática, limitava a capacidade dos cientistas europeus em formular agendas de pesquisa.

Se a busca do reconhecimento internacional exigiu que os "curadores coloniais", para mantermos a terminologia utilizada por Sheets-Pyenson, enviassem coleçôes para museus europeus - e Goeldi manifestou explicitamente essa idéia em um dos seus relatórios institucionais (Goeldi, 1895a:220-221) esse reconhecimento dependia também, em grande parte, da capacidade local em ocupar o que Ritvo (1997) denominou de "vácuo de autoridade científica", ou seja, da habilidade dos "curadores coloniais" em se impor como especialistas em um assunto não dominado pela ciência européia.

No caso de Goeldi, pretendeu firmar-se como especialista em zoologia amazônica. As disputas intelectuais em que se envolveu, abordadas em outro 
lugar (Sanjad, 2005), tinham um claro fundo político que pode ser comparado a um território contestado, ou seja, a um espaço ou um domínio reivindicado por mais de uma pessoa ou instituição. ${ }^{6}$ Goeldi obteve o reconhecimento que almejava, mas para conquistar esse "território" precisou lançar mão de algumas "armas", como o fornecimento de espécimes animais e vegetais para cientistas posicionados em instituições centrais; a publicação de textos originais em revistas controladas por esses cientistas; a publicação de artigos escritos por cientistas europeus no Boletim do Museu Paraense; e o desenvolvimento de investigações afinadas com a tradição dos museus de história natural e com as teorias que mobilizavam a comunidade científica européia. Assim, o zoólogo capitalizou-se com o interesse que a maior floresta tropical do planeta despertava na Europa, acessando debates e círculos mais amplos a partir de seu posto na Amazônia. Foi com este perfil que Goeldi elevou o Museu Paraense e consolidou seu lugar na rede internacional de museus.

Contudo, as questôes taxonômicas e biológicas relativas à fauna brasileira estavam longe de ser um assunto pacífico. Além do conhecimento disponível ainda ser objeto de controvérsia, havia poucos cientistas trabalhando com o assunto e menos ainda pesquisando in loco, etapa fundamental para a formação de coleçôes e obtenção de dados biológicos e ambientais. Os próprios zoólogos ressentiam-se da insuficiência de fontes e da provisoriedade das conclusóes, sendo obrigados a recorrer constantemente aos viajantes do início do século XIX, como Johann Natterer (1787-1843), e a deixar em aberto os problemas que exigiam maior esforço de investigação. A essa situação acrescente-se a dimensão do trabalho a realizar, já claramente perceptível no final do século, quando todas as previsões sobre a biodiversidade neotropical extrapolaram os cálculos mais exagerados.

Nas suas publicações, Goeldi fez inúmeras considerações sobre a fragilidade do conhecimento científico da fauna brasileira, bem como sobre a

\footnotetext{
6 A metáfora do "território contestado" também é inspirada em Ritvo (1997:61-63), que a utilizou ao analisar os significados políticos inseridos no ato da classificação zoológica na segunda metade do século XIX, associando o domínio colonial com a posse intelectual do território: "Nomear [uma espécie] constituía uma forte, se metafórica, reivindicação de posse, não apenas das espécies novamente batizadas, mas também, por implicação, de seu território nativo (...). Para os zoólogos, a descoberta e, especialmente, a descrição de novas espécies forneciam sólidas recompensas, incluindo a oportunidade de escolher o binômio latino do organismo, o qual deveria a partir daí ser formalmente citado com o nome do denominador adicionado entre parênteses. Por meio desse ato, indivíduos reivindicavam a posse intelectual do animal, em paralelo com a reivindicação territorial de seus governos."
} 
inexistência, no país, de especialistas em número suficiente para levar adiante a gigantesca tarefa de classificar a biodiversidade local. ${ }^{7}$ A motivação do zoólogo em escrever livros de divulgação, como "As Aves do Brasil" (1894b) e o "Álbum de Aves Amazônicas" (1900-1906), está diretamente relacionada à percepção de que somente um esforço coletivo dos brasileiros poderia mudar esse estado de coisas - e de que era seu dever incentivar o estudo da natureza no País. Como afirmou no seu livro sobre as aves, tinha a esperança de que pudesse chamar "novos amigos para a observação séria da natureza (...), quer no interesse puramente científico, quer no interesse mais geral e econômico (...)" (Goeldi, 1894b:632).

No dia 22 de março de 1907, Goeldi deixou definitivamente o Brasil. Na sua carta de demissão fez uma breve avaliação dos treze anos em que ficou à frente do Museu Paraense e ressaltou, sobretudo, a transformação verificada na instituição e a autonomia científica de que gozara. Goeldi deixava, de fato, um museu inteiramente diferente do que encontrara em 1894, incluindo os vínculos da instituição com o poder local. Esses vínculos são claros na Carta Circular, evidenciando o projeto político atuante na Primeira República, que tinha na instrução pública e no cultivo das ciências algumas de suas prioridades (Sanjad, 2005).

Nesse sentido, tanto quanto as referências acadêmicas e científicas, as relaçóes políticas de Goeldi foram fundamentais para a construção do Museu Paraense nas duas primeiras décadas republicanas. O próprio Goeldi reconheceu a importância dessas relaçóes na sua carta de demissão, pedindo ao governador para "não encarar o museu como uma instituição que desde já tivesse atingido o seu último grau de desenvolvimento e que necessitava apenas dos cuidados de manutenção, mas de favorecê-lo com atenção aumentada, cercando-o sempre dos recursos e garantias para o crescimento positivo e constante, tanto quanto permitirem as condições gerais de prosperidade pública”.

Com essas palavras, Goeldi apontou o caminho para a sobrevivência do Museu Paraense, associando a capacidade da instituição em absorver as trans-

\footnotetext{
A contratação de pesquisadores estrangeiros para o Museu Paraense estava diretamente relacionada a isso. Goeldi exigia a formação superior em Ciências Naturais, curso que não existia no Brasil. No final do século XIX, a especialização das ciências naturais e o desenvolvimento da pós-graduação, principalmente na Alemanha, já não permitiam o trabalho amador e diletante. Dos oito cientistas que Goeldi contratou, apenas dois retornaram para a Europa, Friedrich Katzer (1861-1925) e Hermann Meerwarth. Os demais se estabeleceram no Brasil e se tornaram referências para gerações de cientistas brasileiros, como Jacques Huber, Adolpho Ducke, Gotfried Hagmann e Emília Snethlage.
} 
formações no âmbito da ciência com o apoio político. Em razão da crise financeira que se abateu sobre a Amazônia na década de 1910, as expectativas de Goeldi não seriam concretizadas, mas aquelas duas esferas permaneceriam atuantes nas sucessivas reformas pelas quais o Museu Paraense passou ao longo do século XX. Foi esta marca institucional que se tornou referência, história e memória de longa duração, quando, por exemplo, a Revolução de 1930 e o contexto pós-guerra alçaram novamente o Museu Paraense à linha de frente da política (Maio et al., 2005). Na década de 1950, mesmo em crise financeira, foi visto como um centro de pesquisa a ser recuperado no momento em que se debatia, em âmbito internacional, o conhecimento científico sobre a Amazônia e o papel da ciência no futuro da região. Novamente re-qualificado, foi absorvido pelo Estado brasileiro e vinculado ao nascente Conselho Nacional de Pesquisas, em abril de 1955.

Carta-Circular de Emílio Goeldi. Rio de Janeiro, 22 de março de 1894. Publicada no Boletim do Museu Paraense de História Natural e Etnografia, Belém, volume 1, fascículo 1, p. 8-10, setembro 1894 .* $^{*}$

Ilmo. Sr.

Tenho a honra de levar ao conhecimento de V.Sa. que a autonomia criada pela República para os diversos Estados do Brasil e a iniciativa própria assim despertada - em contraste vivo com a situação lamentável que vigorava durante o império, onde Sul e Norte tinham por assim dizer de pedir no Rio de Janeiro autorização e licença para qualquer progresso - já maduraram mais um precioso fruto pela decisão do Governo Estadual do Pará de criar um MUSEU DE HISTÓRIA NATURAL E DE ETNOGRAFIA "no pé dos bons estabelecimentos congêneres".

No Sul do Brasil o Estado de S. Paulo foi o primeiro a reconhecer a necessidade de um Museu próprio a cuja testa foi colocado pessoa benemérita das ciências naturais - o Sr. Dr. Hermann von Ihering, meu colega e amigo. No Norte da República, no Pará, quase simultaneamente e de 
modo independente nasceu idêntica idéia, concebida em boa hora pelo Sr. Dr. Lauro Sodré, Dig. ${ }^{\text {mo }}$ Governador, sempre zeloso do progresso do seu Estado natal. Já no ano decorrido tinha-me sido dirigida a pergunta se eu estaria inclinado a encarregar-me da criação e direção de um Museu. Anuindo eu ao convite, foi lavrado o decreto no dia 31 de Janeiro de 1894.

Conforme este decreto as minhas propostas sobre o fim, a administração, etc., do novo Instituto foram aceitas e fiquei incumbido da direção do mesmo.

A carta particular que acompanha a nomeação, como todos os documentos relativos a esta questão e oriundos da pena de tão esclarecida autoridade, respira o sentimento ardente e a profunda inteligência da relevância do assunto "que tão de perto se relaciona com o nosso futuro, pelo muito que pode influir para a elucidação de partes obscuras da ciência e pelo muito que pode contribuir para o desenvolvimento do ensino popular". A mesma carta é outrossim notável pelo modo franco, com o qual se declara que se trata antes da criação nova do que de uma reforma daquilo que até agora figurava com o nome de Museu do Pará. É este o teor literal:

"Verá que digo CRIAR, pois o que temos nem de Museu merece o nome, tão pouco é, tão desalinhado e fora de regra e longe de ciência anda aquilo tudo que dói o ver o contraste entre esta tamanha pobreza acumulada e a enorme riqueza que anda à mão no seio da natureza aqui”.

Tais palavras, juntamente com a promessa oficial de apoio enérgico e de todos os auxílios morais, são para animar-me a ativar vivamente a solução da honrosa tarefa. A minha boa vontade encontra mais um considerável robustecimento na consciência de estar assaz preparado por investigações científicas no Brasil durante dez anos e de achar-me bastante a par das coisas do País.

O Governo tem em vista um edifício apropriado e com capacidade bastante para permitir o desenvolvimento e aumento das coleções.

Julgo poder interpretar bem nitidamente as intenções do Governo Estadual, dizendo que o Museu Paraense será principalmente e em primeira linha um INSTITUTO PARA A HISTÓRIA NATURAL DO AMAZONAS, UM ESTABELECIMENTO QUE SE PROPŌE OBSERVAR, COLECIONAR, DETERMINAR E TORNAR CONHECIDOS OS OBJECTOS DA NATUREZA INDÍGENA. 
Prestará igualmente toda a atenção ao RAMO ETNOGRÁFICO, visto que se trata de região altamente interessante neste sentido. A Zoologia e a Botânica sobretudo - ciências minhas prediletas - prometem fornecer um campo de trabalho extraordinariamente opulento e a preencher as lacunas científicas, deixadas por investigadores e viajantes como Humboldt, Wallace, Bates, Martius, Spix, Natterer, Agassiz e outros, estará no alto do meu programa de trabalho. Cogita-se seriamente NA FUNDAÇÃO de MODESTA ESTAÇÃO BIOLÓGICA no Amazonas com uma filial fora, na costa atlântica (talvez em Bragança) e o estudo intensivo de problemas que tenham alguma conexão direta com a economia social (como por exemplo o da fauna ictiológica do Amazonas e da costa) é um postulado que desde o princípio se impõe pela sua importância intrínseca.

Estou firmemente resolvido a cultivar e a fazer reverter em benefício do novo Instituto, que me é confiado, todas as múltiplas relações amigáveis que particularmente tenho cultivado até agora com Museus estrangeiros e especialistas em todas as partes do mundo. Questóes e problemas que dizem respeito às ciências naturais do Amazonas figurarão d'ora em diante no primeiro plano da minha atividade, e não descuidarei de meio algum que se me afigure como apropriado para tornar o Museu do Pará uma instituição, onde serão recebidos e dados com o maior prazer todos os incitamentos científicos em proveito do Interior como do Exterior. Peço o auxílio dos meus correspondentes neste empenho, e principalmente rogo o favor da remessa benévola do material literário, que tenha qualquer ponto de contato com o meu futuro campo de trabalho, como, em segunda linha, de tudo aquilo que tenha alguma relação com um dos ramos da história natural do Brasil e da América do Sul no sentido mais amplo. Claro é que os Ilmos. Srs. Correspondentes receberão em permuta os trabalhos que o Museu for publicando.

Com subida estima e consideração de V. Sa. Att. ${ }^{o}$ Cr. ${ }^{\text {do }}$ e Ven..$^{\text {dor }}$

\section{Dr. Emilio Augusto Goeldi.}

Rio de Janeiro, 22 de Março de 1894. 
Ofício de Emílio Goeldi ao Secretário de Estado da Justiça, Interior e Instrução Pública. Belém, 7 de março de 1907. Arquivo Guilherme de La Penha, Museu Paraense Emílio Goeldi. Gestão Emílio Goeldi (1894-1907).*

O estado uns anos para cá insatisfatório da minha saúde, para a melhora do qual, a juízo de especialistas de além-mar, impõe-se como condição primordial a mudança de residência debaixo do clima equatorial para um país da zona temperada, de par com a necessidade inadiável de superintender pessoalmente a educação e o ensino dos meus filhos - dever paternal, ao qual sinto ter de cuidar mais do que me foi possível até agora - maduraram em mim a resolução de resignar o cargo de diretor efetivo do Museu Estadual, pedindo ao alto governo a minha exoneração.

Não me é fácil dar este passo, que representa o resultado final de uma verdadeira colisão de deveres: é a vitória da reflexão sóbria sobre o ascendente das inclinações pessoais e o mágico poder da vida habitual, ou, em outras palavras, da linguagem de filosofia moral, um ditame do imperativo categórico.

De fato, errônea seria a suposição que semelhante conjuntura fosse do meu gosto. Perto de treze anos de labutação indefessa, necessária aliás e indispensável mesmo para a fundação e a solidificação dos alicerces deste honroso monumento de cultura intelectual e belo templo de ciência, qual o representa o Museu Estadual, lapso de tempo pequeno perante a história universal, mas abrangendo o período o melhor e de mais vigor de minha vida individual, deviam forçosamente contribuir para identificar-me cada vez mais com a tarefa do Museu, chegando cedo a mais íntima e perfeita comunhão de interesses. É a expressão da pura verdade e do real estado das coisas, se constatamos, que os liames entre o estabelecimento e o seu diretor foram e são de cordialidade inabalada e de toda durabilidade, tanto que excluem a hipótese sequer de um estremecimento eventual ou de um destrato leviano. Julgo dever arquivar para sempre e para todos os efeitos esta minha declaração, que embora eu me veja casualmente obrigado, por motivos de força maior, de deixar o Pará, considero isto apenas como uma deslocação material, sem embargo e detrimento de continuidade e harmonia espirituais.

* A ortografia foi atualizada. 
É meu firme propósito prosseguir na Suíça, o meu país natal, para onde tenciono retirar-me e onde ligar-me-ei à Universidade de Berna, na elaboração de considerável cabedal de materiais científicos relativos à história natural e etnografia amazônica, ficando tais estudos concernentes à natureza brasílica sempre no primeiro plano da minha atividade, se a Divina Providência me for concedendo faculdade e folga para semelhante gênero de trabalho ainda durante alguns anos.

Afigura-se-me neste momento como uma necessidade de proceder a um prospecto sumário e um exame rápido da atual situação. Instrutivo é neste sentido o confronto entre o conteúdo da carta circular que dirigi ainda do Rio de Janeiro em 22 de maio de 1894 ao mundo científico acerca do meu programa, do meu primeiro relatório sobre o estado do Museu por mim encontrado ao assumir o cargo (28 de junho de 1894), do primeiro regulamento do Museu reorganizado (Decreto de 2 de julho de 1894) e do segundo regulamento, atualmente vigente, emanado de reforma posterior em virtude dos decretos No. 1.114 de 26 de janeiro de 1902 e No. 1.272 de 26 de janeiro de 1904. Aí estão os grandes marcos lapidares, assinalando exteriormente períodos notáveis e datas memoráveis da história do nosso estabelecimento, para a qual aliás a fonte de informação mais detalhada reside na série já respeitável dos nossos relatórios anuais.

Evitando entretanto de entrar em pormenores e limitando-nos aos dados e fatos de importância maior, a resposta à pergunta, qual a face da vida museal que porventura apresenta a maior discordância entre o compromisso inicial e ideal sonhado no princípio e o resultado real de hoje não pode causar-nos embaraço. Qualquer destas faces, quer a da completação [sic] do pessoal de diversas categorias, quer a do alargamento territorial, quer a do aperfeiçoamento material interior e exterior, inclusive o aumento de edifícios, quer a da faculdade para investigações de laboratório como para viagens e explorações no campo, quer a do poder de expansão literária e os meios para uma publicidade adequada e digna, quer finalmente a do levantamento dos créditos científicos e sociais do estabelecimento em geral, qualquer uma destas faces pode suportar tranquilamente o exame; nada ficou propriamente estacionário, por toda parte houve movimento e nota-se progresso; parcela alguma ficou sem merecer o seu quinhão de solicitude e carinhosa atenção. Lados há, cujo estado 
atual pouco se distancia do ideal sonhado e da perfeição aspirada, pelo menos sob o ponto de vista da incoacta [sic] liberdade de ação, e com justo orgulho ouso apontar entre estes, por exemplo, para o da atividade literária - as publicações. Outros lados, na verdade, há, e eis-me no ponto onde eu queria chegar, cujo aspecto atual não me satisfaz ainda e que francamente reconheço como atrasados e imperfeitos. Se vejo o Museu do Pará, hoje, comparável a uma árvore grande e vigorosa, de frondosa copa, não posso contudo calar que há umas tantas falhas nesta copa e que há certos galhos, que não foram desenvolvendo-se pari passu com os outros, perturbando assim a simetria. Devo comunicar que nunca os perdi de vista e posso acrescentar ao mesmo tempo, que se não consegui sanar tais lacunas e eliminar tais imperfeições, apesar dos meus ingentes esforços, atribuo-o simplesmente à circunstância, que a Divina Providência tinha resolvido de outro modo.

Quero dizer que, se resigno o meu cargo, não o faço com a pretensão ingênua de deixar uma obra de todo concluída, absolutamente perfeita. Muita coisa resta ainda por fazer, grandes complementos esperam de ser realizados; há muito para completar e arredondar. Não é, por conseguinte, tarefa de mera conservação do status quo, que lego ao meu sucessor: já no fato, que houve melhoramentos importantes almejados, cuja realização não consegui, ou porque o tempo não chegou, ou por adversidade de circunstâncias exteriores, reside um estímulo de própria iniciativa e abrese um vasto campo para cometimentos originais.

Se aludi a isto, com vistas ao meu digno sucessor, peço vênia para declarar ao alto governo por sua vez, que sempre fui partidário da sentença de um dos escritores dos mais autoritativos [sic], na América do Norte, em assuntos museais: "A finished Museum is a dead Museum". ${ }^{8}$ De fato, a idéia de um museu acabado, pronto, refratário ao fenômeno de crescimento, intuspecção e assimilação não se coaduna nada com a noção atual de um estabelecimento, que quer merecer tal nome. Estagnação, se não é idêntico com podridão e morte, também não é cousa muito diversa, porque contém o germe para ambos. Se for permitido ao atual diretor formular

8 N.A.: a frase é do zoólogo e historiador da ciência George Brown Goode (1851 - 1896), diretor do United States National Museum a partir de 1887, e apareceu no livro The Principles of Museum Administration, de 1895. 
ainda um desejo e conselho concernente ao futuro do Museu, seria a calorosa recomendação aos Altos Poderes do Estado, de não encarar o museu como uma instituição que desde já tivesse atingido o seu último grau de desenvolvimento e que necessitava apenas dos cuidados de manutenção, mas de favorecê-lo com atenção aumentada, cercando-o sempre dos recursos e garantias para o crescimento positivo e constante, tanto quanto permitirem as condições gerais de prosperidade pública.

Apresentando assim o pedido de minha exoneração para o dia 21 de março, data provável da minha partida, tomo, em conformidade com um direito expresso no meu contrato inicial com o Governo, a liberdade de propor como meu sucessor, no cargo efetivo, o meu digno e por tantos títulos recomendável companheiro na nobre cruzada da organização do Museu - o Sr. Dr. Jacques Huber, chefe da seção botânica. Peço para ele encarecidamente a mesma fartura de benevolência, de que eu fui alvo, no exercício das minhas funções e pessoalmente, por parte de tais Governadores sucessivos.

$\mathrm{Na}$ mesma ocasião solicito uma declaração oficial no sentido de aprovação plenária dos atos da minha administração desde a data da reorganização do Museu, sob base científica, e 1894, até a presente data da minha resignação. Valor todo especial assumiria para mim um tal documento se ele viesse em forma alargada, incluindo um juízo, um que o Alto Governo manifestaria o grau de satisfação relativa à minha gerência, caso que uma apreciação neste sentido for julgada merecida e constituindo matéria de equidade.

Aproximando-se outrossim a época, onde tem de realizar-se diversos Congressos científicos internacionais, na esfera de interesses de alguns dos ramos cultivados pelo nosso Museu, como seja o Congresso de Zoologia (Boston, Estados Unidos), o de Americanismo (Quebec, Canadá), o de Geografia (Genebra), o de Ornitologia (Bruxelas) e tencionando eu tomar parte, à vista dos repetidos e insistentes convites emanados das respectivas comissões organizadoras, agradável ser-me-ia uma orientação sobre a questão se há conveniência ou não em ser representado o Museu Estadual do Pará, e, no caso afirmativo, se o Governo deseja investir-me da qualidade de delegado oficial. 
Qualquer que seja a resolução que o Alto Governo do Estado, em sua sabedoria, queira tomar na atual emergência, não posso eximir-me de confessar desde já de que o padrão, de que servir-me-ei do meu ponto de vista subjetivo e individual, para medir o valor intrínseco, será o da absoluta espontaneidade.

Em ofício adicional tenciono lembrar à atenção benévola do Governo ainda certas providências relativas ao quadro do pessoal do Museu, providências que adquirem oportunidade por ocasião e em virtude da minha retirada.

\section{Emilio A. Goeldi}

\section{Referências bibliográficas}

Brölemann, H., Dous myriapodos notáveis do Brazil. Boletim do Museu Paraense de História Natural e Etnografia, Belém, 3(1): 65-71, 1900.

Dahl, Fr., "A Fauna do Pará", Boletim do Museu Paraense de História Natural e Etnografia, Belém, 1(4): 357-375, 1896.

Dantes, M.A., Institutos de Pesquisa Científica no Brasil, in: Ferri, M.G., e Motoyama, S. (orgs.). História das Ciências no Brasil. v.2. São Paulo, EPUEdusp, 1979-1980, p.341-380.

Forel, A., A Fauna das Formigas do Brasil. Boletim do Museu Paraense de História Natural e Etnografia, Belém, 1(2): 89-143, 1895.

Goeldi, E.A., Chelonios do Brazil (Jabotys - Kágados - Tartarugas). Boletim do Museu Paraense de História Natural e Etnografia, Belém, 4(4): 699-756, 1906. 
, On Myiopatis semifusca, a small Neotropical Tyrant-bird, harmful to Tree-culture as a Disseminator of the parasitic Loranthaceae. The Ibis, Londres, ser. VIII, v.V, n.XVIII, p.169-179, 1905.

, Lacertílios. Lagartos do Brasil. Boletim do Museu Paraense de História Natural e Etnografia, Belém, 3(3/4): 499-560, 1902a.

, Estudos sobre o desenvolvimento da armação dos veados galheiros do Brazil (Cervus paludosus, C. campestris, C. wiegmanni). Belém, Museu Paraense de História Natural e Etnografia, 1902b.

, Album de Aves Amazônicas. Supplemento illustrativo à obra "Aves do Brazil". Três Fascículos. Belém, Museu Paraense de Historia Natural e Ethnographia, 1900-1906.

, Verzeichnis der bisher wissenschaftlich beschriebenen Neuen Tier- und Pflanzenformen welche während der Jahre 1884-1899 in Brasilien (Staaten Rio de Janeiro, Minas Gerais, São Paulo, Espirito Santo, Bahia und Pará). Com sete Suplementos. Bern, Buchdruckerei Jent \& Co., 1899-1904.

, Primeira contribuição para o conhecimento dos Peixes do valle do Amazonas e das Guyanas. Boletim do Museu Paraense de História Natural e Etnografia, Belém, 2(4): 443-488, 1898.

, Contornos para a avifauna do Pará e da Amazônia inferior; conforme o material dos três colleccionadores mais importantes Natterer, Wallace, Layard. Boletim do Museu Paraense de História Natural e Etnografia, Belém, 1(4): 336-356, 1896 .

, Lancear de olhos sobre a fauna dos repteis do Brazil. Boletim do Museu Paraense de História Natural e Etnografia, Belém, 1(4): 402-432, $1896 \mathrm{~b}$.

, Relatório apresentado pelo Director do Museu Paraense ao Sr. Dr. Lauro Sodré, Governador do Estado do Pará. Boletim do Museu Paraense de História Natural e Etnografia, Belém, 1(3): 217-239, 1895a.

, Os Myriapodos do Brazil (embuás e centopéias). Boletim do Museu Paraense de História Natural e Etnografia, Belém, 1(2): 157-167, 1895b.

, Carta-Circular. Boletim do Museu Paraense de História Natural e Etnografia, Belém, 1(1): 8-10, 1894 a.

, As Aves do Brazil (Monographias Brasileiras II). Primeira Parte. Rio de Janeiro, Alves \& Cia., 1894b. 
, Estudos aracnológicos relativos ao Brasil. Boletim do Museu Paraense de História Natural e Etnografia, Belém, 1(1): 32-39, $1894 \mathrm{c}$.

, Breve notícia acerca de alguns vermes interessantes do Brasil. Boletim do Museu Paraense de História Natural e Etnografia, Belém, 1(1): 40-44, 1894d.

Os Mammiferos do Brazil (Monographias Brasileiras I). Rio de Janeiro, Alves \& Cia., 1893.

, Zur Orientierung in der Spinnenfauna Brasiliens. Mitteilungen der Naturforschenden Gesellschaft des Osterlandes, Altenburg, v. V, p. 200-248, 1892.

Goeldi, E.; Hagmann, G.A., Prodromo de um Catálogo Crítico, Comentado da Coleção de Mamíferos no Museu do Pará (1894-1903). Boletim do Museu Paraense de História Natural e Etnografia, Belém, 4(1): 38-122, 1904.

Gounelle, E., Um mez de caça coleopterologica no Pará. Boletim do Museu Paraense de História Natural e Etnografia, Belém, 2(1): 70-77, 1897.

Hagmann, G., As Aves Brasilicas mencionadas e descriptas nas obras de Spix (1825), de Wied (1830-1833), Burmeister (1854) e Pelzeln (1874) na sua nomenclatura scientifica actual. Boletim do Museu Paraense de História Natural e Etnografia, Belém, 4(2/3): 198-308, 1904.

Lista das aves indicadas como provenientes da Amazônia nos 27 volumes do "Catalogue of Birds of British Museum" de Londres (1874-1898). Boletim do Museu Paraense de História Natural e Etnografia, Belém, 3(3/4): 276-327, 1902.

Lopes, M.M. O Brasil descobre a pesquisa cientifica. Os museus e as Ciências Naturais no século XIX, São Paulo: Hucitec, 1997.

Maio, M.C.; Sanjad, N.; Drummond, J.A. Entre o global e o local: a pesquisa científica na Amazônia do século XX. Ciência \& Ambiente, Santa Maria (RS), v.31, p.147-166, 2005.

Meerwarth, H., Símios (macacos) do Novo Mundo. Boletim do Museu Paraense de História Natural e Etnografia, Belém, 2(2): 121-154, 1897.

Museu Paraense de História Natural e Etnografia, Regulamento do Museu Paraense. Boletim do Museu Paraense de História Natural e Etnografia, Belém, 1(1): 22-27, 1894. 
Nyhart, L.K. Natural history and the 'new' biology, in: Jardine, N.; Secord, J.A.; Spary, E.C. (orgs.). Cultures of natural history. Cambridge, Cambridge University Press, p.426-443, 1996.

Ritvo, H., The Platypus and the Mermaid and other Figments of the Classifying Imagination. Cambridge, Mass., Harvard University Press, 1997.

Sanjad, N., A Coruja de Minerva: o Museu Paraense entre o Império e a República, 1866-1907. Rio de Janeiro, Casa de Oswaldo Cruz/Fundação Oswaldo Cruz, 2005 (Tese de Doutorado).

Schwartzman, S., Formação da Comunidade Científica no Brasil. São Paulo, Nacional; Rio de Janeiro, FINEP, 1979.

Sheets-pyenson, S., Cathedrals of Science. The Development of Colonial Natural History Museums during the Late Nineteenth Century. Kingston, McGill/ Queen's University Press, 1988.

Snethlage, E., Catálogo das Aves Amazônicas. Boletim do Museu Paraense de História Natural e Etnografia, Belém, 8: 1-530, 1914.

Studer, T., Exame do material de Canides (cães e raposas) colleccionado na região Amazonica pelo Museu Goeldi no Pará. Boletim do Museu Paraense de História Natural e Ethnographia, Belém, 4(1): 107-118, 1904.

Thomas, O., Exame de uma collecção de Chiropteros (Morcegos) do Pará. Boletim do Museu Paraense de História Natural e Ethnographia, Belém, 4(1): 101-106, 1904.

Wallace, A.R., Os Símios (macacos) da Amazônia. Boletim do Museu Paraense de História Natural e Etnografia, Belém, 1(4): 375-381, 1896.

Wasmann, E., Os hóspedes das formigas e dos térmites ("cupim") no Brasil. Boletim do Museu Paraense de História Natural e Etnografia, Belém, 1(3): 273-324, 1895. 